\title{
Effect of Knitted Bamboo Structures Dyed With Natural Colorants on Ultraviolet Radiation Protection
}

\section{Sri Vidhya ${ }^{1 *}$ and V. Bhanu Rekha²}

${ }^{1}$ Department of Fashion Technology, Sona College of Technology, Salem, Tamil Nadu, India

${ }^{2}$ Department of Fashion Technology, Kumaraguru College of Technology, Coimbatore, Tamil Nadu, India

\begin{abstract}
The incidence of skin cancer has been increasing at an alarming rate over the past several decades. While there are many factors involved in the onset of melanoma and non-melanoma skin cancers, overexposure to ultraviolet radiation (UVR) has clearly been identified as an important factor. Apart from avoidance of the sun, the most frequently used form of UV protection is the application of sunscreens. Secondly, the most frequently recommended form of UV protection is the use of hats, and proper selection of clothing. The ultraviolet properties of textiles dyed with synthetic dyes have been widely reported in literature. However, there are limited studies on the ultraviolet protection level of eco-friendly fabrics dyed with natural colorants.

This study reports the Ultraviolet Protection Factor (UPF) of bamboo fabric with three different knit structures dyed with natural colorants of plant origin. The bamboo fabrics were dyed with two natural colorants namely Annatto Gold and Eclipta Green. The dyeing parameters were optimised. The Ultraviolet Protection Factor of the fabric with respect to fabric construction, weight, thickness and dyeing was measured in-vitro using Ultraviolet Transmission Analyzer, standard AATCC - 183. The results indicate that there is positive correlation between the weight of the fabric and Ultraviolet Protection Factor. Similarly, thicker the fabric more is the protection. Dyeing with natural colorants dramatically increased the UV protection of all three fabric constructions. Thus, dyeing bamboo fabrics with natural colorants increases the ultraviolet protection of the fabrics and can be considered as an effective protection against ultraviolet rays.
\end{abstract}

Keywords: Ultraviolet Protection; Ultraviolet Protection Factor; Bamboo Fabric; Annatto Gold; Eclipta Green

\section{Introduction}

High, short-term exposure to ultraviolet radiation from the sun causes sunburns and long-term exposure leads to skin cancer. The National Toxicology Program of U.S, Department of Health and Human Services has classified ultraviolet radiation as a known human carcinogen [1]. A primary reason for the increased incidence of skin cancer is attributed to ozone depletion. Each one percent decrease in ozone concentration is predicted to increase the rate of skin cancer by $2 \%$ to $5 \%[2]$.

Other reasons for the skin cancer can be traced to lifestyle changes such as excessive exposure to sunlight during leisure activities, for example, playing outdoors and swimming in the case of children and fishing in the case of adults. In the case of agricultural and other outdoor workers, exposure to the sun is an occupational hazard as they have no choice about the duration of their exposure to the sun [2-4]. UV Radiation is defined as "that portion of the electromagnetic spectrum between $\mathrm{x}$ rays and visible light" [5].

The ultraviolet radiation band consists of three regions: UV-A (320 to $400 \mathrm{~nm}$ ), UV-B (290 to $320 \mathrm{~nm}$ ), and UV-C (200 to $290 \mathrm{~nm}$ ). UV-C is totally absorbed by the atmosphere and does not reach the earth. UV-A causes little visible reaction on the skin but has been shown to decrease the immunological response of skin cells [2]. UV-B is most responsible for the development of skin cancers [2].

Other than drastically reducing exposure to the sun, the most frequently recommended form of UV protection is the use of sunscreens, hats, and proper selection of clothing. Unfortunately, one cannot hold up a textile material to sunlight and determine how susceptible a textile is to UV rays. Even textiles which seem to be non- light transmitting may pass significant amounts of erythema, inducing UV irradiation [3].

In accordance with most studies, the researchers have studied that the type of fiber used to construct a textile can have a substantial effect on the ultraviolet protection factor, especially for white and undyed fabrics [6].

A research on Ultraviolet Protection Factor of cotton fabrics dyed with colorants of plant and insect origins suggests that a positive correlation was observed between the weight of the fabric and their ultraviolet protection values. Thread count appears to negatively correlate with ultraviolet protection factor. Dyeing with natural colorants dramatically increased the protective abilities of all three fabric constructions [7].

There are herbs which possess antioxidant character which help to protect body cells from the damaging effects of oxidation. Factors like stress, aging and pollution causes high level of free radicals in body which damage DNA and causes heart-diseases or cancer or stroke. Substances like vitamin E, vitamin C, or beta carotene act as antioxidant nutrients in the body. Vitamin $\mathrm{E}$ and beta-carotene protect cell membranes and vitamin $\mathrm{C}$ removes free radicals from inside the cell.

*Corresponding author: M Sri Vidhya, Assistant Professor, Department of Fashion Technology, Sona College of Technology, Salem, Tamil Nadu, India, Tel: 9788312384; E-mail: vidhya_muthu@yahoo.co.in

Received April 04, 2012; Accepted May 11, 2012; Published May 13, 2012

Citation: Sri Vidhya M, Bhanu Rekha V (2012) Effect of Knitted Bamboo Structures Dyed With Natural Colorants on Ultraviolet Radiation Protection. J Textile Sci Eng 2:115. doi:10.4172/2165-8064.1000115

Copyright: (C) 2012 Sri Vidhya M, et al. This is an open-access article distributed under the terms of the Creative Commons Attribution License, which permits unrestricted use, distribution, and reproduction in any medium, provided the original author and source are credited. 
Antioxidants work in several ways: they may reduce the energy of the free radical, stop the free radical from forming in the first place, or interrupt an oxidizing chain reaction to minimize the damage caused by free radicals. The two natural colorants, namely, Annatto Gold and Eclipta Green of plant origin are selected for dyeing which are found to have high level of antioxidants (Figure 1).

\section{Annatto - plant profile}

Annatto is from the family Bixaceae (Achiote family). It is called Sindurapushpi in Tamil, Sinduri in Bengali, Kunkum in Kannada, and Annatto in English. Annatto grows to a height of 2-5 meters and is well distributed in Karnataka, Andhra Pradesh, Assam, Tamil Nadu, and Orissa.

Annatto dye is used mostly in dairy industry in coloring butter, cheese, ghee, chocolate, ice cream in medicines and in making boot polishes. The color is also used in making bindi and kunkum.

Annatto dye is basically a red orange pigment known as Bixin, extracted from the seed coat which is inside a prickly heart-shaped pod. Approximately 50 seeds grow inside of the pod. Depending on the color of the flowers, the seedpod is either green or red; the seeds have the same coating in both. The red color is due to apo-carotenoids that are in the seed epidermis. These seeds are processed to obtain the orange-yellow pigments, bixin and norbixin (carotenoids), as dye for the food, cosmetic and soap industries (Figure 2).

Annatto's carotenoids are more than just "pretty". They are powerful antioxidant compounds believed by scientists and medical researchers to aid in combating a variety of ills caused by free radicals and toxins, both of which occur naturally as byproducts of human metabolism. Antioxidants are believed to support heart health and to combat carcinogens and provide good UV protection [8].

The principal components of Annatto are the carotenoids bixin and norbixin [9]. Bixin, the monomethyl ester of a dicarboxylic carotenoid $\left(\mathrm{C}_{25} \mathrm{H}_{30} \mathrm{O}_{4}\right)$, is the naturally occurring form and norbixin $\left(\mathrm{C}_{24} \mathrm{H}_{26} \mathrm{O}_{4}\right)$ is the saponified form of the same carotenoid. They are chemically related to lycopene and saffron. As the ratio between bixin: norbixin in Annatto can vary, this provides flexibility for its use in a wide variety of applications and a range of colours from orange to red (Figure 3).

\section{Eclipta - plant profile}

Eclipta Prostrata belongs to family Asteraceae. It is also known as Bhringaraj and Karisilakanni in Tamil and Eclipta in English, which is a common weed throughout India ascending up to $6000 \mathrm{ft}$. The genus name comes from the Greek word meaning "Deficient," with reference to the absence of the bristles and awns on the fruits. The herb has been used in the treatment of infective hepatitis in India [10] and snake venom poisoning in Brazil. It has been reported that the leaves of this herb are used in the case of gastritis and respiratory disorders like cough and asthma. In addition, the crude form of the herb is reported to have anti-inflammatory, anti-fungal and anti-hepato toxic properties.

Main active principle constituents are wedelolactone, desmethylwedelolactone [10], furanocoumarins, and oleanane and taraxastane glycosides [11]. The methanolic extract of Eclipta Green is a dark green solution with characteristic odor. Its principal constituent contains wedelolactone [12] and demethyl wedelolactone which were isolated by column chromatography. The presence of flavones apigenin and luteolin, as the flavone-7-O-glycoside and the flavone-
C-glucosides are the main colorant. [13] The chemical compounds which give Eclipta its medicinal value are Wedelolactone and Demethylwedlolactone. Wedelolactone is a furanocoumarin with the chemical formula $\mathrm{C}_{16} \mathrm{H}_{10} \mathrm{O}_{7}$. It is a yellow-green solid with a molecular weight of 314.3 [14] (Figure 4).

The constituents' wedelolactone and desmethylwedelolactone were tested for its antioxidant property. Antioxidants play an important role in inhibiting and scavenging radicals, thus providing protection to humans against infection and degenerative. Antioxidants are compounds that help to inhibit many oxidation reactions caused by free radicals such as singlet oxygen, superoxide, peroxyl radicals, hydroxyl radicals and peroxy nitrate there by preventing or delaying damage to the cells and tissues.

It has been observed that the extract exhibited strong activity with the increase in polarity (with reference to organic solvent), indicating that polyphenols or flavanone or flavanoids may play important roles in the activities [15].
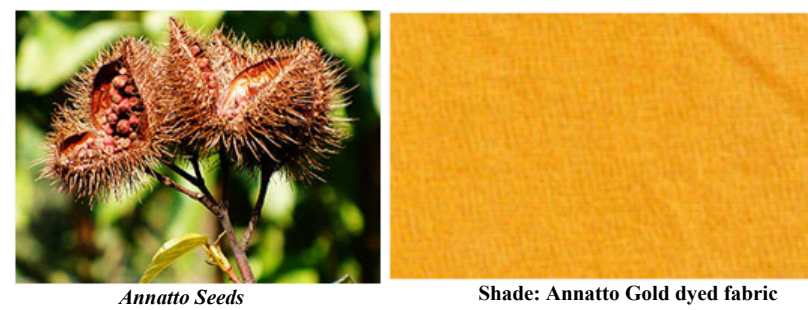

Figure 1: Eclipta green of plant origin and annatto gold dye.<smiles>CC(=O)C=CC(C)=CC=CC(C)=CC=CC=C(C)C=CC=C(C)C=CC(=O)O</smiles>

cis-Bixin

Figure 2: Structure of bixin

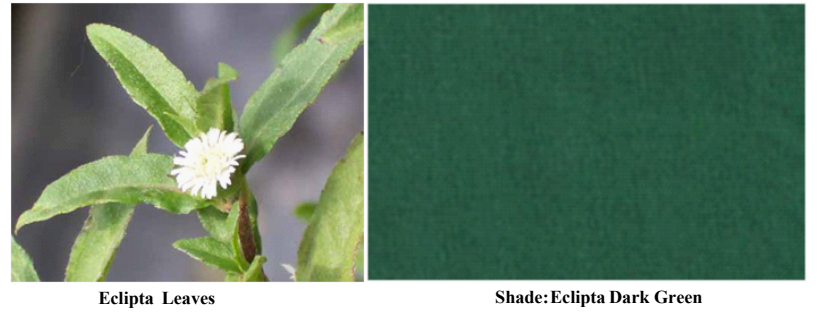

Figure 3: Eclipta Leaves and Eclipta Dark Green shade.<smiles>COc1cc(O)c2c(c1)oc(=O)c1c3cc(O)c(O)cc3oc21</smiles>

Figure 4: Wedelolactone Chemical Structure. 


\section{Materials and Methods}

\section{Materials}

Selection of substrate: Bamboo is the fabric selected for the study as it is the most preferable fiber type worn during the summer next to cotton. Hence $100 \%$ bamboo is chosen for the study.

Fabrics made of bamboo fibres have been growing in popularity, because it has many unique properties and is more sustainable than most textile fibres. Bamboo fabric is light and strong and has excellent wicking properties. Bamboo fabric is very soft and can be worn directly next to the skin. Bamboo fabric is a natural moisture wicking agent.as the cross section of a bamboo fiber is filled with multible microholes and microgaps. Moisture is taken from the body, on contact, and then instantly evaporates. Bamboo is naturally cooler in summer and warmer in winter. Hence, bamboo fabrics were chosen for the study to increase the UV- protecting abilities of fabric by means of fabric structure and dyeing.

\section{Methods}

Extraction of the annatto gold dye: The golden yellow dye is extracted from seeds of Annatto by soaking and squeezing in water to dissolve the fleshy seedcoat which contains the dye. The dye is only partially soluble in water and produces a turbid solution. The solution is then concentrated by heating and is subsequently cooled to form red crystals. The solution was allowed to ferment for about a week, and the dye that has settled at the bottom of the vessel is then separated and dried.

Extraction of eclipta green dye: This is a dark greenish dye which is extracted from the Eclipta leaves. The leaves were collected and washed thoroughly with water to remove any impurities. After drying at room temperature, the leaves were ground into fine powder. $100 \mathrm{~g}$ of the powder was weighed and taken in a round bottom flask and 500 $\mathrm{ml}$ of ethanol in the ratio 40:60 was added to it. The flask was heated in a water bath at $60^{\circ} \mathrm{C}$ for 60 mintues. The solution was then filtered to obtain crude dyestuff [16].

The crude dyestuff is distilled to get $1 / 3^{\text {rd }}$ of the solution using the Soxhlet apparatus at $70^{\circ} \mathrm{C}$ for $3 \mathrm{hrs}$. In this process ethanol is recovered and the concentrated dye is obtained. The solution is kept overnight at room temperature for precipitation. The precipitation in ethanol water is obtained by decanting the solution. The obtained particles are dried in the oven overnight at $60^{\circ} \mathrm{C}$.

Optimisation of dyeing conditions: The dyeing parameters such as temperature, time, $\mathrm{pH}$, and material-to-liquor ratio $(\mathrm{M}: \mathrm{L})$ were optimized. Separate sets of experiments were conducted for optimizing each parameter in which the parameter to optimize was varied under a certain range while the rest of the parameters were kept constant. The optimisation was carried out on single jersey bamboo fabric.

Optimization of dyeing temperature: Three experiments were performed for the optimization of dyeing temperature for each plant in which dyeing was done at $70^{\circ} \mathrm{C}, 80^{\circ} \mathrm{C}$ and $90^{\circ} \mathrm{C}$ respectively for 60 minutes. The M:L ratio was 1:30. Optimum temperature was determined based on the maximum dye absorption.

Optimization of dyeing time: After optimizing the dyeing temperature, the time for dyeing was optimized by performing five experiments in which dyeing was done at $80^{\circ} \mathrm{C}$ for Annatto and Eclipta separately for 30,45 and 60, minutes. The M:L ratio was 1:30. Maximum value of dye absorption was recorded.

Optimization of M:L ratio: Six experiments were performed for the optimization of dyeing M:L ratio for each plant. For this purpose dyeing was done at $80^{\circ} \mathrm{C}$ for 60 minutes for Annatto and Eclipta separately with M:L ratio, 1:30, 1:40 and 1:45.

Optimization of $\mathbf{p H}$ value: Three experiments for optimizing the $\mathrm{pH}$ level were performed. The $\mathrm{pH}$ was changed to aqueous media and then to acidic ( $\mathrm{pH} 4)$ and alkaline ( $\mathrm{pH} 10)$ by adding Acetic acid and Sodium carbonate respectively. The absorbency values were recorded before and after dyeing in respective media.

Mordants: Natural dyes require chemicals in the form of metal salts to produce an affinity between the fabric and the dye and these chemicals are known as mordants [17]. Mordants facilitate the bonding of the dyestuff to the fibre. Although metallic salts work well to fix the dyes and provide an alternate palette, they are health hazard and produce toxic waste which requires special disposal.

Selection of mordant: The mordant selected for dyeing the bamboo fabric is alum. Alum mordant used with natural dyes, is generally Aluminium Potassium Sulfate $\left(\mathrm{K}_{2} \mathrm{SO}_{4} \cdot \mathrm{Al}_{2}\left(\mathrm{SO}_{4}\right)_{3} .24 \mathrm{H}_{2} \mathrm{O}\right)$. Alum mordants are used as they deepen the color of the dye in a fabric. It improves light and washfastness of all natural dyes and keeps colours clear. Thus, alum mordant was used in the dyeing process to get deep shades of yellow from Annatto and green from Eclipta.

Mordanting: Fabric was mordanted prior to dyeing by treating with alum at boil for 45 minutes. The liquor ratio is 1:40 and alum concentration was $10 \%$ on weight of the fabric. After mordanting, fabric was squeezed thoroughly and dyed. below:

Fabric dyeing: The optimised dyeing conditions are tabulated as

$\begin{array}{lllll}\text { Dye } & \mathbf{p H} & \text { M:L } & \text { Temperature } & \text { Time } \\ 4 \% \text { owf } & 4 & 1: 40 & 80^{\circ} \mathrm{C} & 60 \text { mintues }\end{array}$

The material - to- liquor ratio was 1:40. Fabrics were introduced into the dyeing solutions at room temperature. Temperature was then raised to $80^{\circ} \mathrm{C}$ and dyeing continued at the boil for 60 minutes. After dyeing, fabrics were rinsed in deionized water, washed using a nonionic detergent and air dried.

Calculation of percentage of dye absorption: The optical density of the liquor was measured before and after dyeing of Mesta fibres. The percentage of dye absorption was calculated using the following formula.

Percentage dye Absorption =

Optical density before dyeing - Optical density after dyeing Optical density before dyeing

Among the values of dye absorption, the absorbency value with maximum absorption was selected.

Evaluation of ultraviolet protection factor : The dyed fabrics were subjected to UV testing. UPF's were measured in-vitro using a Labsphere UV-100 F Ultraviolet Transmission Analyzer according to standard AATCC - 183. 


$$
U P F=\frac{E D}{E D_{m}}=\frac{\sum_{290 n m}^{400 n m} E_{\lambda} S_{\lambda} \Delta \lambda}{\sum_{290 n m}^{400 n m} E_{\lambda} S_{\lambda} \Delta \lambda}
$$

UPF is defined as the ratio of the average effective UV irradiance calculated for unprotected skin to the average UV irradiance calculated for skin protected by the test fabric. The higher the value, the longer a person can stay in the sun until the area of skin under the fabric becomes red (Table 1). The UPF for the test fabric can be calculated as:

$\mathrm{E}_{\lambda}=$ erythemal spectral effectiveness

$\mathrm{S}_{\lambda}=$ solar spectral irradiance in $\mathrm{Wm}^{-2} \mathrm{~nm}^{-1}$

$\mathrm{T}_{\lambda}=$ spectral transmittance of fabric

$\Delta_{\lambda}=$ the bandwidth in $\mathrm{nm}$

$\lambda=$ the wavelength in $\mathrm{nm}$

The cumulative effects of the fabric structure and dye on the ultraviolet protection level are studied.

\section{Results and Discussion}

\section{Optimization of dyeing process}

Optimization of dyeing temperature: The effect of temperature on the dyeability of bamboo fabric with Annatto extract and Eclipta's alkaline extract was conducted at various temperatures $\left(70-90^{\circ} \mathrm{C}\right)$. As shown in Figure 5, it is clear that the percentage of dye absorption increases with the increase in dyeing temperature and reaches a maximum value at $80^{\circ} \mathrm{C}$ then it decreases. This increase in dye uptake can be explained by fabric swelling and deaggregation of dye molecules into single molecule at higher temperatures [18] (Figure 5).

Optimization of dyeing time: Effect of dyeing time on dye absorption percentage of single jersey bamboo fabric is shown in Figure 6 . The longer the dyeing time, higher is the colour absorption

\begin{tabular}{|l|l|l|}
\hline UV Protection Category & UPF Ratings & $\%$ Blocking \\
\hline Good protection & $15-24$ & $93-96 \%$ \\
\hline V. Good protection & $25-39$ & $96-97 \%$ \\
\hline Excellent Protection & $40-50+$ & $97-99 \%$ \\
\hline
\end{tabular}

Table 1: Ratings of Ultraviolet Protection Factor.

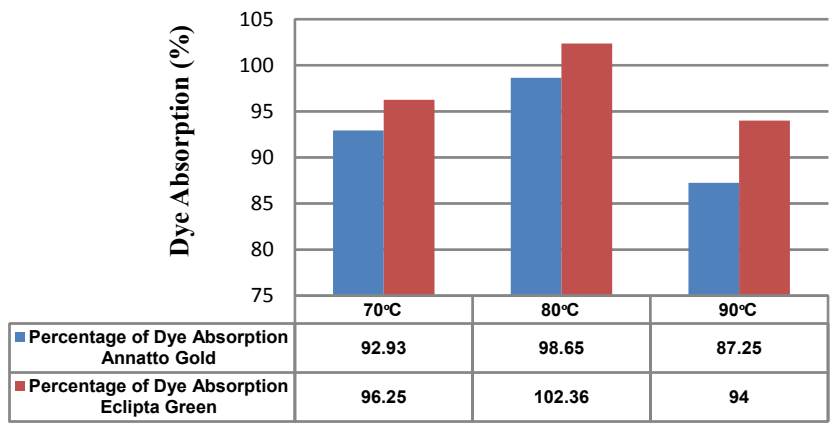

Figure 5: Optimisation of Dyeing Temperature.

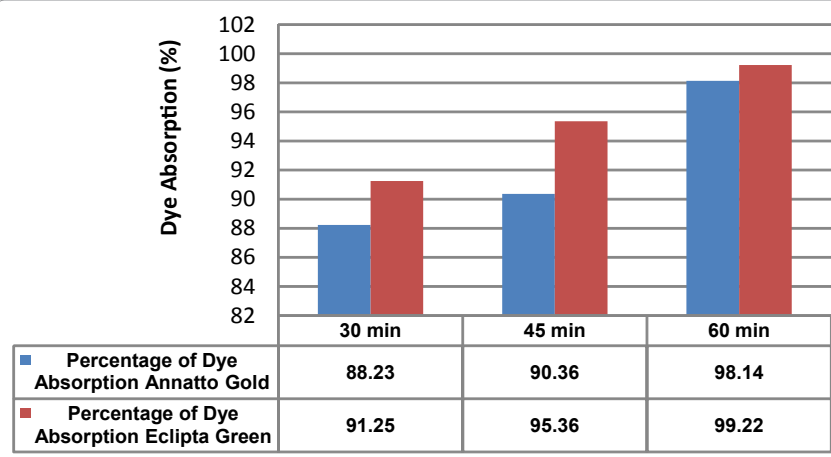

Figure 6: Optimisation of Dyeing Time.

until dye exhaustion attains equilibrium and a decrease in the dye intake was observed after further increase in time from 60 minutes. This effect was observed due to shift in equilibrium of colourant from fabric to dyebath [19].

Optimization of M:L ratio: The effect of material to liquor ratio on dye ability of single jersey bamboo fabric was conducted at M:L 1:30, 1:40, and 1:45 ratios. As shown in Figure 7, it is clear that the dye absorption percentage increases with increase in M:L ratio and the optimum M:L ratio was 1:40. Low absorption value with low $\mathrm{M}: \mathrm{L}$ ratio could be explained that with the congestion of dye molecules at lower $\mathrm{M}: \mathrm{L}$ ratio which compelled dye molecules to strike each other rather than with fabric for bond formation.

Optimisation of $\mathbf{p H}$ value of Dye bath: The effect of different $\mathrm{pH}$ level on dyeability of single jersey bamboo fabric was observed using aqueous media, acidic $(\mathrm{pH} 4)$ and alkaline ( $\mathrm{pH} 10)$ media. From Figure 8 , it can be observed that the percentage of dye absorbance is high in acidic medium ( $\mathrm{pH} 4)$.

Thus the optimised conditions for dyeing bamboo fabrics with Annatto Gold and Eclipta Green are:

$\begin{array}{llll}\text { M:L } & \text { Temperature } & \text { Time } & \mathbf{p H} \\ 1: 40 & 80^{\circ} \mathrm{C} & 60 \text { mintues } & 4\end{array}$

\section{Effect of fabric structure on the ultraviolet protection factor}

Three fabric structures were chosen to cover the gamut of basic knit structures. They were single jersey, interlock and rib structures. Fabric weight was measured according to ASTM D3776-96 and thickness was measured according to ASTM D1777-96 standards [6].

Fabric characterization parameters and UPF values prior to dyeing are listed in Table 2. Based on the classification parameters the undyed fabrics of three structures cannot be rated as offering any degree of protection since their UPF values were less than 15 . The undyed interlock structure with a UPF of 14.23 may be rated as having Good UV Protection (as it is close of 15). The UPF values of the undyed fabrics can be explained in terms of fiber composition and fabric construction. In terms of fiber composition it is known that undyed cotton, linen, acetate, and rayon fabrics afford poor protection against UV radiation [20]. Fabric construction parameters of weight and thickness show a positive correlation with UPF values. Higher the weight and thicker the fabric, higher is the degree of protection afforded by the fabric.

Accordingly, the interlock knit structure with a weight of $209 \mathrm{~g} / \mathrm{m}^{2}$ 
and a thickness of $0.63 \mathrm{~mm}$ has the highest UPF value followed by the rib knit structure which weighed $186 \mathrm{~g} / \mathrm{m}^{2}$ and was $0.60 \mathrm{~mm}$ thick. The single jersey structure with a weight of $163 \mathrm{~g} / \mathrm{m}^{2}$ and a thickness of 0.54 $\mathrm{mm}$ offers no protection against transmittance of UV rays.

The positive correlation between fabric weight and fabric thickness with UPF values can be explained with reference to the closeness of the stitches. This is called as the stitch density. Stitch density is the number of knit stitches occupied in a given fabric area. More the number of stitches, more opaque the fabric is to UV radiation. Stitch density is increased by an increase in weight per unit area. Heavier fabric minimizes UV transmission by virtue of having smaller spaces between the knit stitches, thus blocking more radiation. A related variable is thickness. Thicker, denser fabrics transmit less UV radiation and have a higher cover factor.

\section{Effect of natural dyes on the ultraviolet protection factor}

UPF values and protection categories of the single jersey fabric dyed with the two colorants are listed in Table 3 . Undyed single jersey fabric had consequently a very low UPF value of 9.8. It is evident from the UPF values that the two colorants used in the study caused a dramatic reduction in UV radiation transmission through the single jersey fabric.

The increase in UPF values in the presence of colorant was significant for the Eclipta and Annatto dyed which were classified as having Good UV Protection (UPF values between 15 and 24) to Very Good UV Protection.

Compared to Eclipta, Annato is a light color and therefore these results agree with previous data reported by Reinert et al. [21] who

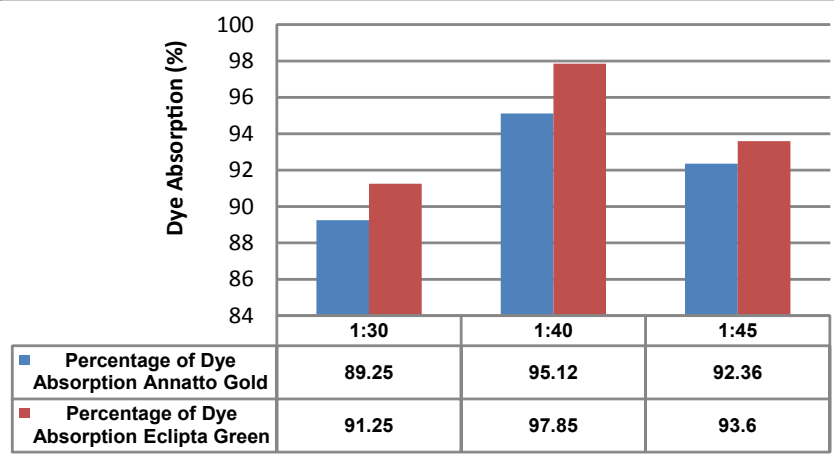

Figure 7: Optimisation of M:L Ratio

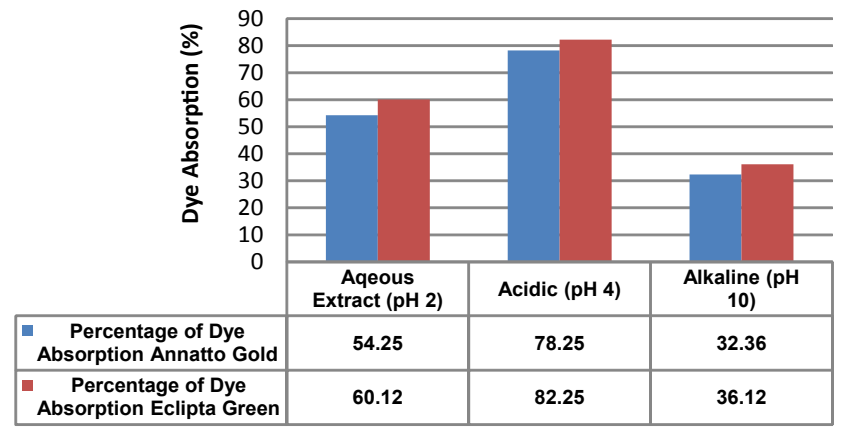

Figure 8: Optimisation of $\mathrm{pH}$ of Dye Bath.

\begin{tabular}{|c|c|c|c|c|c|c|c|}
\hline $\begin{array}{l}\text { S. } \\
\text { No. }\end{array}$ & $\begin{array}{c}\text { Fabric } \\
\text { Structure }\end{array}$ & $\begin{array}{l}\text { Wales per } \\
\text { Inch }\end{array}$ & $\begin{array}{l}\text { Course } \\
\text { per Inch }\end{array}$ & $\begin{array}{c}\text { Weight } \\
\left(\mathrm{g} / \mathrm{m}^{2}\right)\end{array}$ & $\begin{array}{c}\text { Thickness } \\
(\mathrm{mm})\end{array}$ & UPF & $\begin{array}{c}\text { UV } \\
\text { Protection } \\
\text { Class }\end{array}$ \\
\hline 1. & $\begin{array}{l}\text { Single } \\
\text { Jersey }\end{array}$ & 38 & 36 & 163 & 0.54 & 9.8 & No Class \\
\hline 2. & Rib & 34 & 36 & 186 & 0.60 & 12.5 & No Class \\
\hline 3. & Interlock & 47 & 40 & 209 & 0.63 & 14.23 & Good \\
\hline
\end{tabular}

Table 2: Fabric Characterisation Parameters and UPF values of undyed fabric.

\begin{tabular}{|c|c|c|c|}
\hline S. No. & Herbs Used & UPF & UV Protection Class \\
\hline 1. & Undyed - Control Fabric & 9.8 & No Class \\
\hline 2. & Annato Gold & 18.53 & Good \\
\hline 3. & Eclipta Green & 22.56 & Good \\
\hline
\end{tabular}

Table 3: UPF values and protection class of Single Jersey fabric dyed with natural colorants

\begin{tabular}{|c|c|c|c|}
\hline S. No. & Herbs Used & UPF & UV Protection Class \\
\hline 1. & Undyed & 12.5 & No Class \\
\hline 2. & Annato Gold & 26.36 & Very Good \\
\hline 3. & Eclipta Green & 27.2 & Very Good \\
\hline
\end{tabular}

Table 4: UPF values and protection class of Rib fabric dyed with natural colorants.

\begin{tabular}{|c|c|c|c|}
\hline S. No. & Herbs Used & UPF & UV Protection Class \\
\hline 1. & Undyed & 14.23 & No Class \\
\hline 2. & Annato Gold & 34.4 & Very Good \\
\hline 3. & Eclipta Green & 33.02 & Very Good \\
\hline
\end{tabular}

Table 5: UPF values and protection class of Interlock fabric dyed with natural colorants.

showed that light colored fabrics of cotton, silk, polyamide, and polyamide/elastan gave less protection against intense UV radiation.

This is also in agreement with Gies et al. [22] who indicated that dyeing fabrics in deeper shades and darker colors improves sun protection properties. Thus although the studies by Reinert et al. and Gies et al. were done with synthetic dyes their conclusions seem to hold with natural colorants as well.

UPF values and protection categories for the rib structure fabric are shown in Tables 4 . The rib fabric which prior to dyeing was rated as no protection moved to the Very Good UV Protection classification irrespective of the colorant used. Again, it was found that dark colors within the same fabric type transmit less UV radiation than light colors and consequently have higher UPFs.

Table 5 shows the UPF values and protection categories for the dyed interlock structure fabric. The increase in UPF values of the interlock structured fabrics was dramatic in the sense that this structure which prior to dyeing could not be rated achieved the Very good to Excellent UV Protection classification by virtue of its UPF values.

From the above tables it is observed that the fabric dyed with Eclipta dye has high level of UV protection in all three structures. The reason behind it is that the research works have proved that Eclipta leaves have an antioxidant activity of $77.62 \%$ which when compared to Annatto is very high. It has been observed that the Eclipta extract 
Citation: Sri Vidhya M, Bhanu Rekha V (2012) Effect of Knitted Bamboo Structures Dyed With Natural Colorants on Ultraviolet Radiation Protection. J Textile Sci Eng 2:115. doi:10.4172/2165-8064.1000115

Page 6 of 6

exhibited strong activity indicating that polyphenols or flavanone or flavanoids play important roles in the antioxidant activities [15].

Also, the dye absorption percentage of Eclipta Green is found to be high when compared to that of Annatto Gold, which is also a reason for having high level of UV protection.

\section{Conclusion}

In the present study, the UV protection of the $100 \%$ bamboo fabric with three different knit structures has been studied. The investigation let us perceive the influence of the fabric parameters on UV protection. Fabric weight and thickness are important predictors of UPF values for undyed bamboo fabrics. In general, it was found that increase in weight and thickness increased the UPF. UPF of undyed fabrics was significantly enhanced by dyeing with natural colorants Annatto Gold and Eclipta Green. The dyeing conditions were optimised to get a high percentage of dye absorption. In addition, the dark colored Eclipta Green provides better protection on account of high UV absorption. Based on the results of this study it can be theorized that single jersey, rib and interlock knitted bamboo fabrics dyed with natural colorants can provide good protection against ultraviolet rays. Denser the fabric and darker the color, more is the protection offered by the fabric.

\section{References}

1. Carcinogens listed in the tenth report. http://ehp.niehs.nih.gov/roc/toc10.html

2. Capjack L, Kerr N, Davis S, Fedosejevs R, Hatch KL, et al. (1994) Protection of humans from ultraviolet radiation through the use of textiles: A Review. Fam Consum Sci Res J 23: 198-218.

3. Rieker J, Guschlbauer T, Rusmich S (2001) Scientific and practical assessment of UV protection. Melliand Textilberichte 7-8: E155- E156.

4. Hatch KL (2001) Fry not! ASTM Standarization News 18-21.

5. http://www.hps.org/hpspublications/articles/uv.html

6. Pailthorpe $M(1998)$ Apparel textiles and sun protection: a marketing opportunity or a quality control nightmare? Mutat Res 422: 175-183.

7. Sarkar AK (2004) An evaluation of UV protection imparted by cotton fabrics dyed with natural colorants. BMC Dermatol 4: 15.
8. Morrison EY, Thompson H, Pascoe K, West M, Fletcher C (1991) Extraction of an hyperglycaemic principle from the annatto (Bixa orellana), a medicinal plant in the West Indies. Trop Georg Med 43: 184-188.

9. Jansen PCM, Cardon D (2005) Dyes and Tannins - Plant Resources of Tropical Africa.

10. Wagner H, Geyer B, Kiso Y, Hikino H, Rao GS (1986) Coumestans as the main active principles of the liver drugs Eclipta alba and Wedelia Calendulaceae. Planta Med 52: 370-374.

11. Singh A, Duggal S, Suttee A, Singh J, Katekhaye S (2010) Eclpita Alba Linn Ancient remedy with therapeutic potential. 1: 57-63.

12. Govindachari TR, Nagaranjan K, Pai BR (1956) J Sci Ind Res 15 B 664.

13. Mithun NM, Shashidhara S, Vivek Kumar R (2011) Eclipta alba (L.) A review on its phytochemical and pharmacological profile. Newsletter 1: 345-357.

14. Biomol Int (2007) Wedelolactone.

15. Karthikumar S, Vigneswari K, Jegatheesan K (2007) Screening of antibacteria and antioxidant activities of leaves of Eclipta prostrata (L). Sci Res Ess 2: 101104.

16. Kulkarni SS, Gokhale AV, Bodake UM, Pathade GR (2011) Cotton Dyeing with Natural Dye Extracted from Pomegranate (Punica granatum) Peel. Univers J Environ Res Technol 1: 135-139.

17. Shanker R, Vankar Padma S (2005) Dyeing with Celosia cristata flower on modified pretreated wool. Colourage 52: 53-56.

18. Shenai VA, Mehra RH (1997) Technol Text Process 2: 159-193.

19. Kamel MM, Reda M, El-Shishtawy, Youssef BM, Mashaly H (2007) Ultrasonic assisted dyeing. IV. Dyeing of cationised cotton with lac natural dye. Dyes Pigm 73: $279-284$

20. Davis S, Capjack L, Kerr N, Fedosejevs R (1997) Clothing as protection from ultraviolet radiation: Which fabric is most effective? Int J Dermatol 36: 374-379.

21. Reinert G, Fuso F, Hilfiker R, Schmidt E (1997) UV-Protecting properties of textile fabrics and their improvement. Text Chem Clrst 29: 36-43.

22. Gies HP, Roy CR, Elliot G, Wang Z (1994) Ultraviolet radiation factors for clothing. Health Phys 67: 131-139. 